This item was submitted to Loughborough's Research Repository by the author.

Items in Figshare are protected by copyright, with all rights reserved, unless otherwise indicated.

\title{
Sleep restriction and serving accuracy in performance tennis players, and
} effects of caffeine

PLEASE CITE THE PUBLISHED VERSION

http://dx.doi.org/10.1016/j.physbeh.2013.07.002

PUBLISHER

(C) Elsevier Inc.

VERSION

AM (Accepted Manuscript)

LICENCE

CC BY-NC-ND 4.0

\section{REPOSITORY RECORD}

Reyner, Louise A., and James A. Horne. 2019. "Sleep Restriction and Serving Accuracy in Performance Tennis Players, and Effects of Caffeine”. figshare. https://hdl.handle.net/2134/15403. 
This item was submitted to Loughborough's Institutional Repository (https://dspace.lboro.ac.uk/) by the author and is made available under the following Creative Commons Licence conditions.

\section{creative
commons}

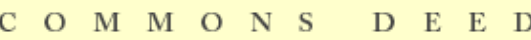

Attribution-NonCommercial-NoDerivs 2.5

You are free:

- to copy, distribute, display, and perform the work

Under the following conditions:

Attribution. You must attribute the work in the manner specified b the author or licensor.

Noncommercial. You may not use this work for commercial purposes.

No Derivative Works. You may not alter, transform, or build upon this work.

- For any reuse or distribution, you must make clear to others the license terms of this work.

- Any of these conditions can be waived if you get permission from the copyright holder.

Your fair use and other rights are in no way affected by the above.

This is a human-readable summary of the Leqal Code (the full license).

\section{Disclaimer 만}

For the full text of this licence, please go to: http://creativecommons.org/licenses/by-nc-nd/2.5/ 


\section{Short Report (Revised)}

\section{Sleep Restriction, Serving Accuracy in Performance Tennis Players, and Effects of Caffeine}

\section{A Reyner \& J A Horne \\ L.A.Reyner@lboro.ac.uk}

Sleep Research Centre

Loughborough University

Leicestershire,

LE11 3TU,

UK

00 441509-223024 


\begin{abstract}
Athletes often lose sleep on the night before a competition. Whilst it is unlikely that sleep loss will impair sports mostly relying on strength and endurance, little is known about potential effects on sports involving psychomotor performance requiring high level cognitive skills necessitating judgement and accuracy, as in tennis, and where caffeine is 'permitted". Two studies were undertaken on the effects of $5 \mathrm{~h}$ sleep (33\%) restriction versus normal sleep, on an objective measure of serving accuracy in semi-professional tennis players. Testing (14:00h-16:00h) for both studies comprised 40 serves into a $(1.8 \mathrm{~m} \times 1.1 \mathrm{~m})$ 'service box' diagonally, over the net. Study 2 was identical to that of Study 1, except that there was an extra sleep restriction condition. All conditions involved a sugar free drink given 30 min before testing, but with the drink for one sleep restriction containing 80mg caffeine (double blind). Study 1 comprised 16 men and women, in a within Ss counterbalanced design (normal versus sleep restriction). Study 2 involved 12 different men and women undergoing three conditions in a latin square design. Conditions were as for Study 1 , with a replicated sleep restriction. All conditions incorporated a sugar-free drink given 30 min before testing, with one restriction including $80 \mathrm{mg}$ caffeine (double blind). Both studies showed significant impairments to serving accuracy following sleep restriction, particularly with women. At this dose, caffeine had no beneficial effect. These results reflect laboratory based, non-sports related findings pointing to detrimental effects of sleep loss on executive function. 211
\end{abstract}

\title{
Key Words
}

Sleep restriction, caffeine, tennis, serving accuracy 


\section{Introduction}

Sleep prior to a competition can be disrupted by anxiety, travel, and jet-lag, and it is not unusual to have had only 4-5h sleep on the night before a competition, including waking up early for 'warm-up' sessions etc. Whilst sleep loss is unlikely to affect cardio-respiratory and muscle function and physical work capacity (eg. [1] [2] [3]) adverse cognitive effects (rather than motor output) are well known (eg. [4] [5] [6] [7]) as are mood changes ([8] [9]).

Athletes are increasingly utilising caffeine (a permitted substance) to enhance physical endurance and physical recovery after strenuous exercise. However, it remains of questionable benefit to sports involving strength and power, such as sprinting ([10] [11]). Although caffeine is effective in overcoming 'sleepiness' as reflected in monotonous and unstimulating performance measures, such as the psychomotor performance test (PVT - [7] [12] [13] [14] [7]), little is known about whether caffeine is effective in counteracting putative sleep loss effects on high level cognitive performance in psychomotor skills involving judgement and accuracy rather than speed, as in tennis serves, for example. As far as we can ascertain this has not been previously investigated.

We report on two studies, a year apart, on the effects of sleep restriction versus normal sleep on an objective measure of serving accuracy (rather than power) in semi-professional tennis players. The first study comprises sleep restriction alone, and the second involves a similar restriction, in an independent group, and compares caffeine with placebo, given double blind

\section{Method - Study 1}

\subsection{Participants}

Sixteen performance tennis players, (8m, 8f), aged 18-22y were recruited from the University's first and second teams, their having represented the University in the British University Sport Association's national competitions. They were good sleepers, having an average habitual sleep duration of between $6.5 \mathrm{~h}$ and $8 \mathrm{~h}$, and were neither morning nor evening types [15]. They scored $<10$ on the Epworth Sleepiness Scale (ESS - [16]), and were modest consumers of alcohol and coffee. They had the procedures fully explained, signed consent forms, and received a gift voucher on completion of the study. The investigation, as well as Study 2, had full approval of the University's Ethical Committee. Participants had been told that the study was looking at the effects of sleep reduction on serving performance, as nothing was known about the topic, and that there may be no effect. Moreover, that we had no preconceptions about the outcome.

\subsection{Design and Procedure}


There were two conditions, normal sleep versus sleep restricted by $2-2.5 \mathrm{~h}$ by delayed bed-time (same rising times), with conditions balanced between participants, and given a week apart. Participants wore wrist-worn Actiwatches Cambridge Neurotechnology, UK] the night before (from 18:00h the evening before) and slept in their normal beds. Actimeters were downloaded and checked for compliance with the required sleep durations (normal vs $5 \mathrm{~h}$ ) the following morning before testing.

For three days and nights prior to experimental periods they kept logs of estimated sleep onset, and morning wakening and rising times, to ensure usual compliance with habitual sleep duration. They had to avoid alcohol and caffeinated drinks for $24 \mathrm{~h}$ before experimental days, and on this morning ate a light breakfast, consisting of cereal or toast but nothing fried. Lunch consisted of water and sandwiches consumed between 12:30 and 13:00h. Testing was between 14:00h and 16:00h, to control for potential circadian effects (cf. [17]), as well as to coincide with the bicircadian 'dip', that would have been enhanced by a prior night's sleep restriction. On arrival at the tennis court participants were allowed a warm up according to their usual requirements, which had to be identical for both testing occasions. They were then given a basket of 40 new Slazenger tennis balls with which to serve. Each service was hit from the participant's desired point on the baseline (replicated on the second occasion).

Participants were asked not to consider their shots as 'first or second serves' but to aim their serve into the set target in the diagonal service box (see below) across the net, which was clearly marked with white masking tape. They were told that a serve would be considered accurate if it passed over the net and hit within the service box opposite. If it touched any of the boundary lines then it was 'out'. They were asked to do their usual best and that there was no demand to deliver in a rush, but at a steady pace.

Of the forty serves, the first 10 were discounted, to allow for any further 'warm-up', although participants were not aware of this. The accuracy (hit or miss) of each serve was logged by an experimenter situated near the target box but out of direct visual range of the participant. Once each participant completed the 40 serves they were debriefed and given some information about the accuracy of their serves, but not given their actual score (this was disclosed after the second condition). Afterwards, they were allowed to 'warm down' at their own discretion.

Participants used their own individual racquet, with string tension approximately between 50 and 65 pounds (cf. [18]).

\section{$\underline{2.3 \text { Apparatus }}$}

The size of the target, located within the service box (see Diagram 1), was determined with the help of the University tennis coach, following a series of pilot tests that would allow an average 
$65 \%$ hit rate by comparable tennis players, under normal conditions. Target dimensions were: $1.8 \mathrm{~m}$ long by $1.1 \mathrm{~m}$ wide.

\section{Method - Study 2}

\section{$\underline{3.1 \text { Participants }}$}

Twelve different performance tennis players $(6 \mathrm{~m}, 6 \mathrm{f})$, age range $19-23$ years, from the same source as for Study 1, who fulfilled identical criteria, were recruited the following year. This group happened to be rather longer sleepers than those for Study 1, but the level of sleep restriction was still 2-2.5h (see Results).

\subsection{Design, Procedure and Apparatus}

There were three conditions, given a week apart, in a repeated-measures, latin square experimental design. Conditions were identical to those of Study 1, except that there were two sleep restriction conditions, incorporating a sugar free drink given 30 min before testing under all three conditions. Under one of the restrictions the drink contained 80mg caffeine, given double blind. This design gave six combinations of the three conditions, with two participants per combination. Participants were instructed as before, but were additionally told that the study was looking at caffeine effects, and that one of the conditions would include a modest dose of caffeine in the drink. Procedures for the 40 serves and the target box specifications were identical to those of Study 1

\section{Results}

\section{Study 1}

Group mean sleep durations (by actimeter) the night before testing, under baseline and sleep restriction were $395 \mathrm{~min}$ (s.e. $8.2 \mathrm{~min}$ ) and $258 \mathrm{~min}$ (s.e. $4.8 \mathrm{~min}$ ) respectively . A paired samples $\mathrm{t}$ test assessing hits (max score $=30$ ) within the service box, and between the two conditions, was significant ( $t=5.98$, df15, $p<001)$, and is evident in Figure 1a. Figure $1 \mathrm{~b}$ also shows these significant differences within genders, (men t=3.67, df 7, p<008; women 5.27, df 7, p<0.001).

\section{Study 2}

Mean sleep durations for baseline, sleep restriction alone and with caffeine were $465 \mathrm{~min}$ (s.e. $10.2 \mathrm{~min}$ ), $325 \mathrm{~min}$ (s.e. $6.8 \mathrm{~min}$ ) and $315 \mathrm{~min}$ (s.e. $7.3 \mathrm{~min}$ ) respectively. Again, there was a clear difference in serving accuracy between normal sleep and the two sleep reduction conditions, as seen in Figure 2a. A repeated measures ANOVA was significant $(F=93.00$, df 2, 22; $p<0.001)$. Although post hoc $t$ tests between pairs of conditions were significant $(p<0.02)$ between baseline and each of the sleep reduction conditions, there was no significant difference between the two sleep reduction conditions, caffeine versus no caffeine. Separate analyses were not undertaken 
within genders owing to the small sample sizes, however, Figure $2 \mathrm{~b}$ shows these outcomes to be similar.

\section{Discussion}

It appears from both studies that sleep reduced by about one third affects serving performance in young men and women players. Although men, here, generally performed better than women, the outcomes with regard to sleep loss were consistent for both sexes. Also it can be seen that inasmuch that Study 2 replicates Study 1 in terms of effects of sleep loss (nil caffeine) versus baseline, the differences between the two conditions are very similar across studies, for both men and women.

Of course, we cannot be certain that the effects of sleep loss are purely cognitive, rather than due to participant 'expectancy' effects. Inasmuch that as coaches tend to advocate the importance of adequate sleep, then players might anticipate poorer performance and apply less effort following sleep reduction, despite our exhortations for them to do their best. However, these findings do seem to reflect laboratory based, non-sports related findings pointing to detrimental effects of sleep loss on executive function $[5,7]$.

Caffeine at the dose given had no effect in improving deteriorating performance, and a larger dose could have been more effective. However, we were restricted in the amount of caffeine able to be given, as it could not be at a pharmacological level, but within acceptable 'social' limits, for example, as found in an average cup of coffee or in a 'functional energy drink' (eg $250 \mathrm{ml}$ can of 'Red Bull'). For tennis players, adequate sleep would seem to be essential, at least for accurate serving performance.

\section{Acknowledgements}

We would like to thank James Cuthell and Christina Birtchnell for their help with data collection 


\section{References}

[1] Reilly T, Deykin T. Effects of partial sleep loss on subjective states, psychomotor and physical performance tests. J Hum Movement Stud 1983; 9: 157-170.

[2] Horne JA, Pettitt AN. Sleep deprivation and the physiological response to exercise under steady state conditions in untrained subjects. Sleep 1984; 7: 168-179.

[3] Reilly T, Edwards B. Altered sleep-wake cycles and physical performance in athletes.

Physiol Behav 2007; 90: 274-284.

[4] Pilcher JJ,Huffcutt Al. Effects of sleep deprivation on performance: a meta-aAnalysis. Sleep 1996; 19: 318-326.

[5] Harrison Y, Horne JA. The impact of sleep loss on decision making - a review. J. Exper. Psychol. - Applied 2000; 6: 236-249.

[6] Coyle E, Martinez V. Sleep, pre-game fatigue, and game performance in female college soccer players. J Sports Science Med 2007; Suppl 10: 107.

[7] Killgore WD. Effects of sleep deprivation on cognition. Prog Brain Res 2010; 185: 105-129

[8] Scott JPR, McNaughton LR, Polman RCJ. Effects of sleep deprivation and exercise on cognitive, motor performance and mood. Physiol Behav; 2006; 87: 396-408.

[9] Minkel JD, Banks S, Htaik O, Moreta MC, Jones CW, McGlinchey EL, Simpson NS, Dinges, DF. Sleep deprivation and stressors: evidence for elevated negative affect in response to mild stressors when sleep deprived. Emotion 2012; 12:115-120

[10] Graham TE. Caffeine and exercise: metabolism, endurance and performance. Sports Med; 2001; 31: 785-807

[11] Paton CD, Hopkins WG, Vollebregt L. Little effect of caffeine ingestion on repeated sprints in team-sport athletes. Med Sci Sport Exercise; 2001; 33: 822-825

[12] Lim J, Dinges DF. Sleep deprivation and vigilant attention. Ann NY Acad Sci 2008; 1129: 305322

[13] Bonnet MH, Balkin TJ, Dinges DF, Roehrs T, Rogers NL, Wesensten NJ. Sleep deprivation and stimulant task force of the American Academy of Sleep Medicine. Sleep 2005; 28: 1163-1187.

[14] Roehrs T, Roth T.Caffeine: sleep and daytime sleepiness. Sleep Med Rev 2007;12:153-62. 
[15] Horne JA, Östberg O. A questionnaire to determine morningness and eveningness in human circadian rhythms. Int J Chronobiol 1976; 4: 97-110.

[16] Johns MW. A new method for measuring daytime sleepiness: the Epworth Sleepiness Scale. Sleep 1991; 14: 540-6.

[17] Atkinson G, Speirs L. (1998). Diurnal Variation in Tennis Service. Percept Motor Skills 1998; 86: 1335-1338.

[18] Bower R, Cross R. String tension effects on tennis ball rebound speed and accuracy during playing conditions. J Sports Sci 2005; 23: 765-771. 


\section{Legends}

Diagram 1 - Layout of target box

Figure 1 - Study 1: upper (a) - group means (standard error bars) for hits within the target box for both conditions (maximum score $=30$ ). Lower b) data as for (a) but sub-divided by gender. There were significant differences between conditions for (a) and ( $b$ - both men and women) see Results.

Figure 2 - Study 2: upper (a) - group means for hits (standard error bars) for the three conditions. Whereas the overall ANOVA was significant (see Results), there was no difference between the two sleep reduction groups. Lower (b) findings as for (a), but for men and women separately 
Diagram 1

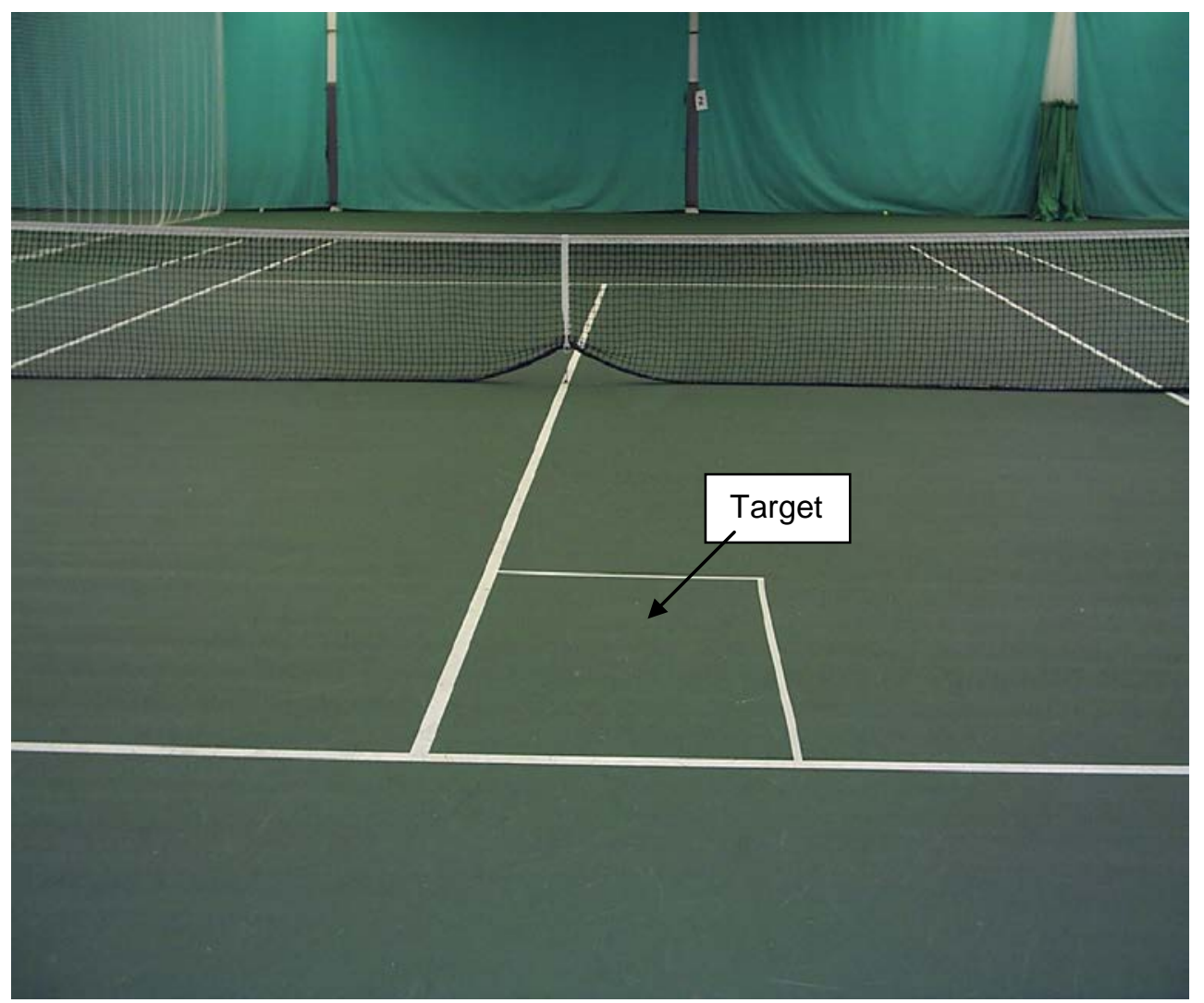


Figure 1a

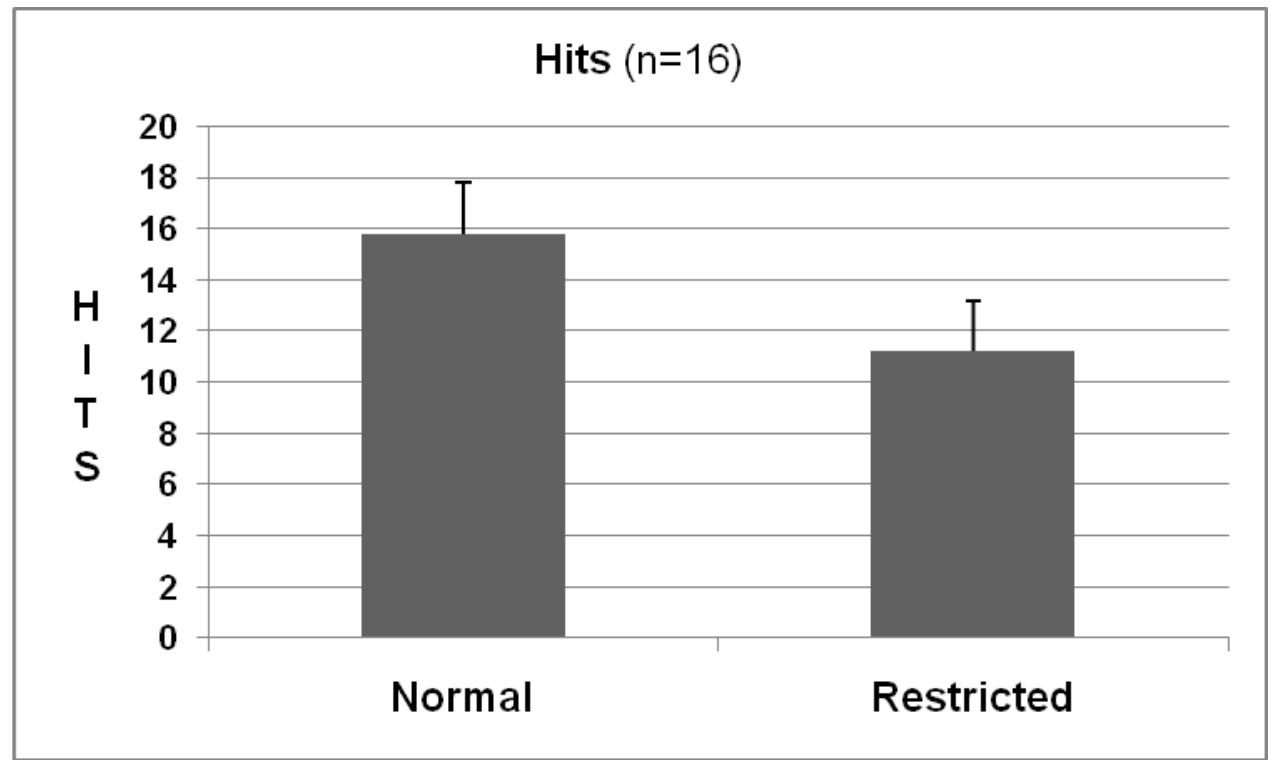

Figure $1 b$

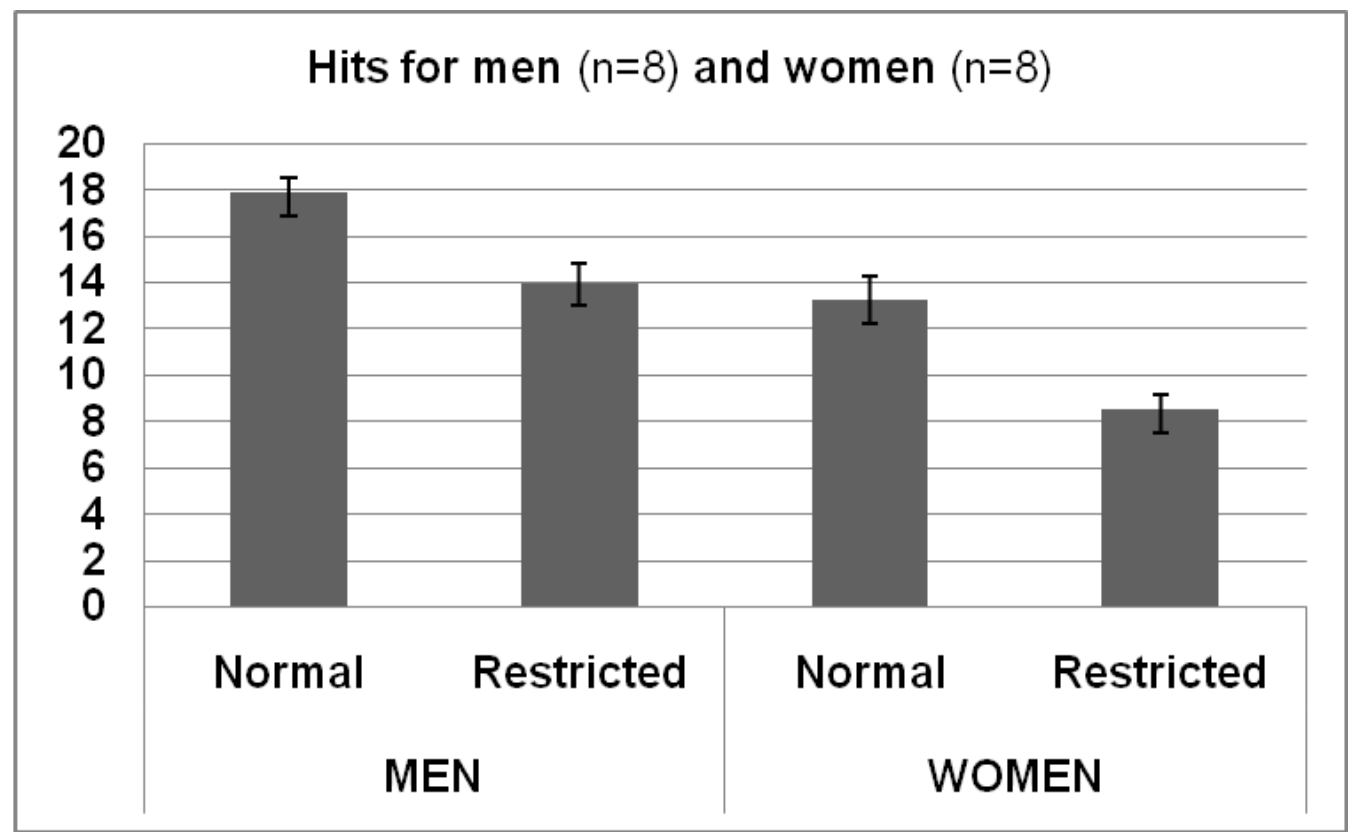


Figure 2a

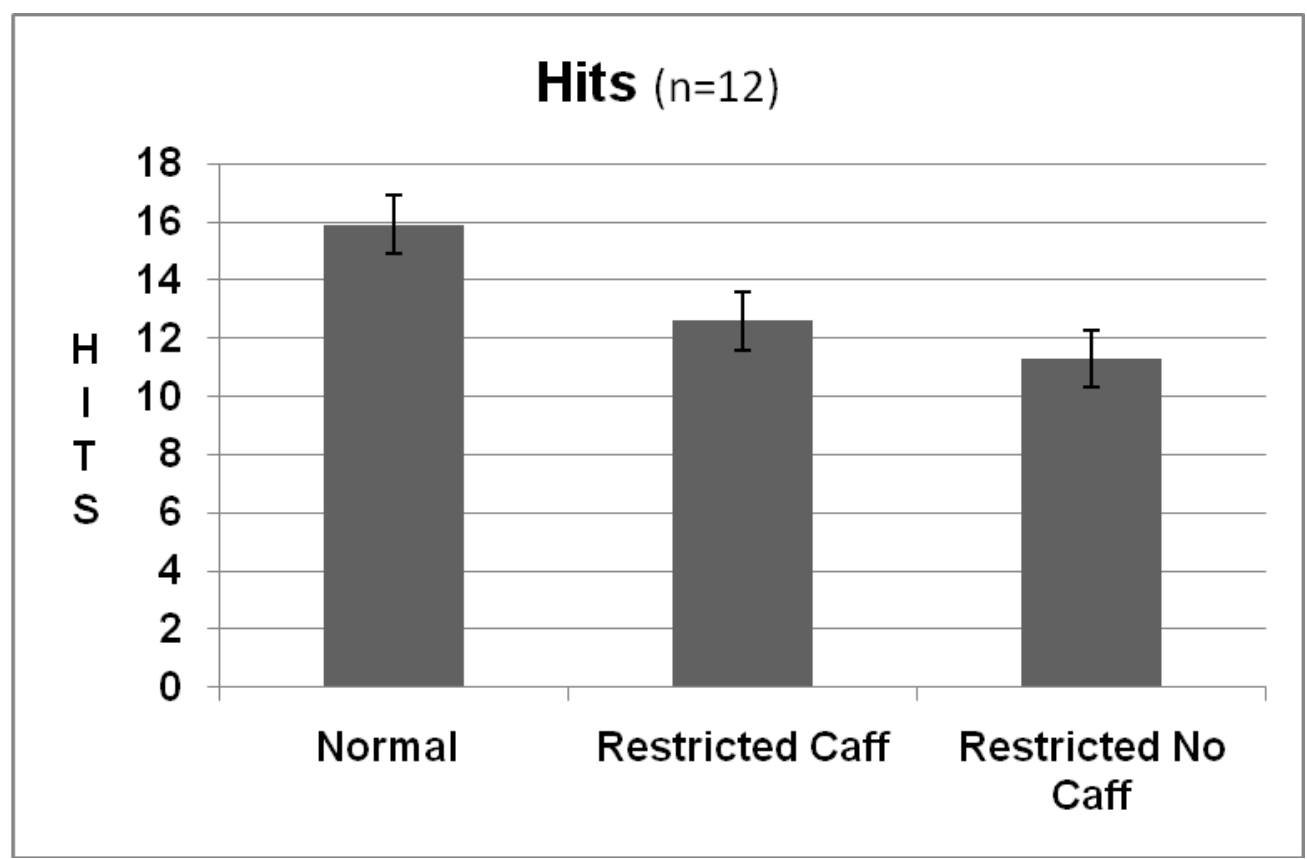

Figure 2b

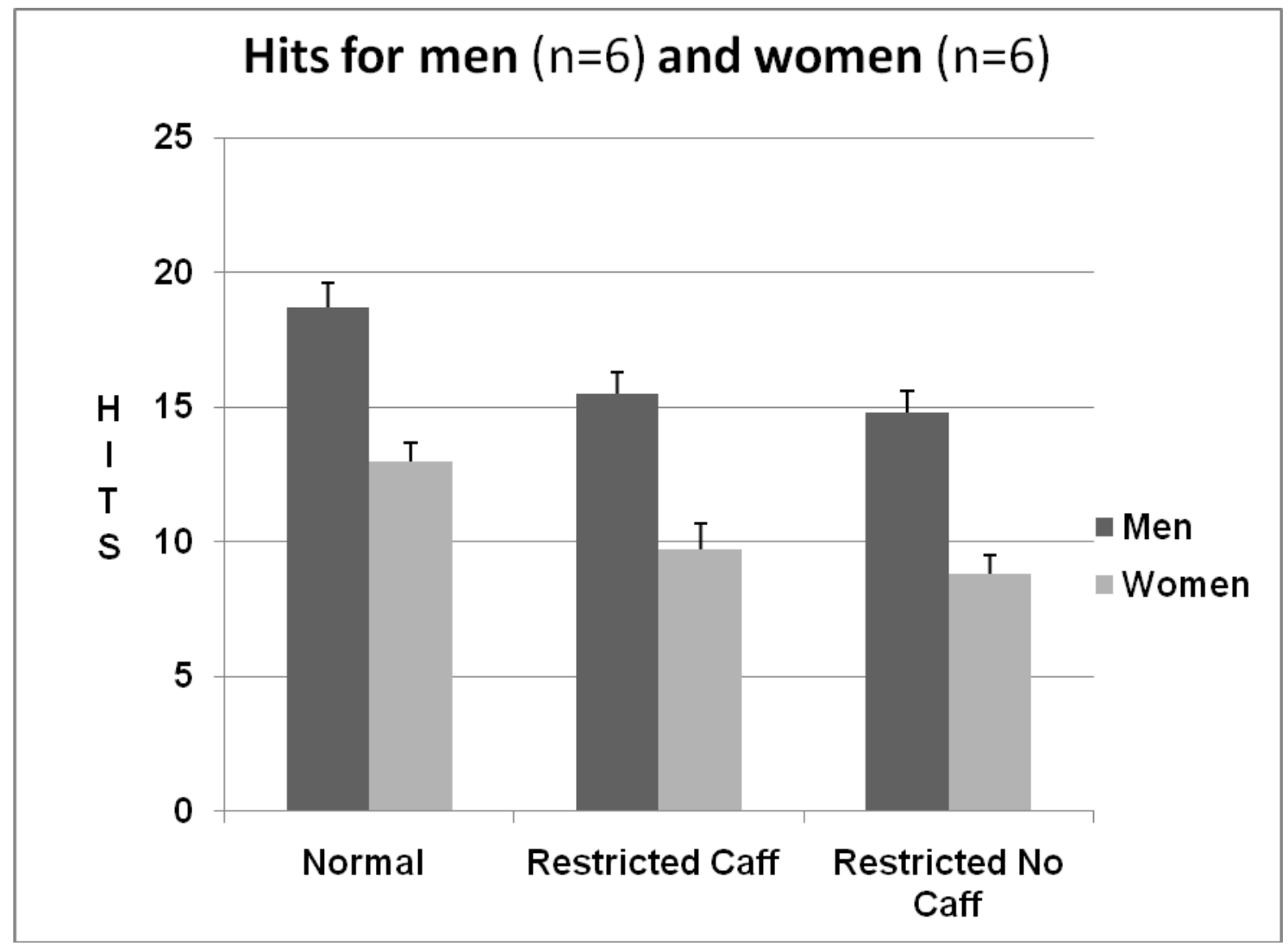

